\title{
Does Tenure Matter For Occupant Experiences Of Low- Energy Housing?
}

\author{
Trivess Moore ${ }^{1}$, Graeme Sheriff ${ }^{2}$, David M. Whaley ${ }^{3}$, Stephen R. Berry ${ }^{3}$, \\ ${ }^{1}$ Royal Melbourne Institute of Technology, Melbourne, VIC, Australia \\ ${ }^{2}$ University of Salford, Greater Manchester, United Kingdom \\ ${ }^{3}$ University of South Australia, Adelaide, SA, Australia \\ trivess.mooredrmit.edu.au
}

\begin{abstract}
International policy settings are looking toward low-energy and near zero-energy homes as a solution to address environmental impacts, particularly anthropogenic climate change. There is increasing research evaluating sustainable housing developments from a technical and occupant perspective. One of the key determinants of household energy use is tenure. However, there is limited research which has looked at if tenure impacts on how occupants experience low-energy homes. This paper contributes to the literature by exploring three low-energy housing developments and exploring the role of tenure in relation to how the households experience the dwellings. The case studies demonstrate that social housing tenants have frustrations with a lack of control over what they could, or could not, do to their low-energy dwellings, in comparison to owner-occupier housing.
\end{abstract}

Keywords: low-energy housing, tenure, occupant experiences.

\section{Introduction}

The requirement to transition to a low carbon or low-energy housing future is well established [1]. Organizations such as the Intergovernmental Panel on Climate Change [2] and United Nations (through their Sustainable Development Goals [3]) have highlighted the role that low-energy housing will play in achieving a more sustainable and equitable future. This position is supported by the increasing evidence of the wide range of benefits that low-energy housing provides to occupants and broader society [4-12].

There are increasing examples around the world of housing developments which deliver significantly improved sustainability and liveability outcomes. More wellknown examples include BedZED in the UK, Solarsiedlung in Freiburg, Germany and zHomes in the US [13-15]. Research into such developments has found they can now be delivered for little, or no, additional costs in comparison to traditional housing while having improved energy efficiency and other sustainability outcomes [8, 1620].

Whilst there has been a large body of research demonstrating the energy and environmental benefits of exemplar low-energy houses from a technical perspective [18, 
21-23], more recently researchers have started exploring how occupants use and experience such dwellings [24-26]. There has also been a stream of research exploring challenges with increasing uptake of sustainability strategies across the housing sector from the perspective of the building owner and/or occupants. For example, the issues of 'split-incentives' for renters and landlords [27-30]. However, this occupant research tends to overlook the simple question of do they like low-energy homes? This paper contributes to the literature by exploring three case studies of low-energy housing exploring the occupant experience and drawing out considerations of tenure.

\subsection{Tenure And The Sustainable Housing Challenge}

There is a strong relationship between household energy use and tenure globally [3134]. For example, Druckman and Jackson [32] found that tenure was a key factor to household energy use in the United Kingdom, Issacs et al. [34] found tenure a factor in New Zealand, Hache et al. [33] found tenure a factor in France, and Mashhoodi [31] noted the link with tenure in the Netherlands. Typically, research has examined the impact on sustainability from three key types of tenure; owner-occupier, private rental and social/public housing [35]. Much of the research points to renters having less control over what actions can be done to the home and less ability to financially take action. Parag et al. [36] argue that that the likelihood of energy efficiency action and change is linked to levels of agency and capacity, and in the case of renters, irrespective of their agency (or interest) for action, their capacity to take action is impaired.

There is an increasing focus on tenure within the policy and research realm in the face of increasing housing supply and affordability challenges globally. For example, rapidly increasing house prices in Australia means that home ownership is further out of reach for many households and a generational shift in financial thinking is seeing increasing numbers of younger people rather spend their money on consumables such as travel and life-style activities than locking themselves into long-term mortgages [37].

Tenure has also been part of the broader sustainable housing policy discussion. There has been a recognition that there are different opportunities and challenges depending on if you are an owner-occupier or if you are a landlord or renter. Owneroccupiers, especially those in detached housing, are seen as having significant opportunities to make modifications to their property to improve sustainability outcomes, although significant capital costs and the disturbance to the home that accompanies retrofit limit the extent to which this is taken advantage of. Whereas there is the issue of 'split incentive' which is seen in rental properties. This is where the landlord pays for a sustainability improvement, but the benefit of that is enjoyed by the renter; this means that private landlords are often reluctant to spend money if they do not see a financial return [35]. The counter argument is that the more a home is environmentally sustainable and thermally comfort, the higher the rent can be charged and the more happy occupants will likely be, reducing the amount of churn and associated costs. However, this lends itself to concerns relating to rent increases and gentrification in the private rented sector. Social housing itself also has a different set of challenges 
with social housing providers often trying to balance the need for more housing with sustainability outcomes [26]. However, social housing often has particular advantages in comparison with individual landlords in the private rented sector, such as the economies of scale enjoyed when carrying out improvements across co-located properties, relatively consistent maintenance regimes across properties, access to technical teams, and availability of temporary accommodation for decanted tenants. Social housing providers tend to also have an interest in tenant welfare and financial health, relating these to social responsibility policies as well as rent arrears reductions.

The research which looks at tenure and sustainable housing tends to focus on the opportunities and constraints of each. However, there is limited research which has looked at if tenure impacts on how occupants experience low-energy homes. This paper contributes to the literature around that through the following case studies.

\section{Method}

To address the aim of this paper, three case studies of occupant's experiences of low-energy housing are presented. Two of the case studies are from Australia and one from the United Kingdom. Each has had broader evaluations and analysis of each development, including technical evaluations of performance, presented elsewhere $[18,20,24,26,38,39]$. This paper however looks at these developments from the perspective of the occupant's tenure and their energy related experiences.

The analysis of each case study draws upon semi-structured interviews with the households $(n=38)$. The interviews explored how occupants were using, and not using, their dwellings from an energy end-use perspective, and how design and sustainability technology elements were impacting on this, including opportunities and limitations due to tenure. Interviews were audio recorded and transcribed. Thematic analysis was conducted to draw out key ideas from the households.

The first case study is of a retrofit of 32 social housing flats across two blocks in Greater Manchester, United Kingdom. These flats were retrofitted in 2015 to a PassivHaus equivalent (EnerPHit) standard. Nine occupants were interviewed in 2016, five of which had lived in the flats prior to retrofit and returned following period in temporary accommodation. The second case study is of four low-energy social houses located in Horsham, regional Victoria, which were constructed in 2012 by the State Government of Victoria to demonstrate exemplar low-energy housing and to inform future minimum building performance requirements. A three-year evaluation of the housing development was conducted between 2012-2015 which included yearly interviews with the occupants in each low-energy dwelling. The third case study comes from a purpose-built environmentally sustainable housing development at Lochiel Park in Adelaide, South Australia. This development contains just over 100 dwellings which were constructed between 2009 - 2017 and which are primarily owneroccupied. The Land Management Corporation (currently known as Renewal SA) was the developer and established, in conjunction with industry and academic experts, the Lochiel Park urban design guidelines developed [UDG] for the area that aimed to significantly reduce: potable water consumption by $78 \%$; delivered energy consump- 
tion by $66 \%$; and greenhouse gas emissions by $74 \%$. This development consists of 80 mainly detached or semi-detached houses and 23 apartments. Twenty-five households were interviewed for this research.

By bringing these case studies together this paper aims to explore the issue of tenure as it relates to how occupants are experiencing their low-energy housing. The cases cover owner-occupied housing and social housing tenures and cover different housing typology including detached housing and medium density apartments/flats as well as retrofit and new build. This allows the paper to explore similarities and different, while recognizing the limitations of generalizing from such a small sample size.

\section{Case study analysis}

\subsection{PassivHaus Standard Retrofit in Manchester, UK}

Social housing provider One Manchester undertook a retrofit of 32 units across two blocks in 2015. The retrofit was undertaken to a PassivHaus standard, regarded as one of the most innovative residential building standards in the world. The retrofit was driven by a need to improve rundown buildings and improve occupant outcomes both within the flats (e.g. lower bills) and around them (e.g. reducing anti-social behavior). Monitored performance from seven of the retrofitted flats found they were performing as expected and were 'highly controllable and comfortable' (Sherriff et al., 2018). During the process, residents were decanted to temporary accommodation when it was found that the work would be more disruptive than anticipated. This case study is distinct from the other two in that it is a retrofit, rather than new build, and in a heating- rather than cooling-dominated climate.

The household interviews found that most households were positive about the end result of the retrofit, especially in relation to the improved thermal performance, reduced energy bills and perceived improvement to health and wellbeing outcomes. They stated for example:

"Previously, when we were here... on a day like this, we would [be] in this room, be sat with coats and, oh my God. Oh, it was horrendous and when we came in here, it's like, wow. It was different. It was warm."

In relation to improved health and wellbeing, one tenant saw improvements in terms of their asthma whilst another remarked that her son had been able to sleep better since the retrofit and that "because of the quietness as well he's got time to study".

However, while the majority of households were pleased with the retrofit, a minority reported issues. For example, in relation to changes to thermal comfort one household raising the issue of draughtiness and another household stated that it could be stuffy at times. There were also different degrees of understanding amongst the residents about the PassivHaus retrofit and how the retrofitted flats and new technologies worked. Despite a range of education being provided to households (including face-to-face meetings and technical information booklets) there was still a level of uncertainty about some elements. While some residents spoke of knowing how to access further assistance, there was a sense that some tenants felt that there was a 
'correct' way to live in the properties "to manage the properly according to how they expect me to manage it". As one resident stated:

"None of us really got the scientific part... and, to be honest, it was very high tech for a lot of people round here."

In addition, some residents expressed frustration over a lack of control they had over their flats post retrofit. This included elements such as having the hot water boilers locked away and only accessible to maintenance staff as well as the circuit breaker powering this locked, so that they could not adjust the temperature of the water as they had done previously or switch the unit off; there were also examples of being told that they could not organize their own window cleaners due to concerns about damaging the façade of the building. Similarly, one resident spoke of how they were not allowed to install their own satellite dish due to the same concerns. Another concern raised was that the retrofit process consolidated energy services at the building level and residents were no longer able to select their own energy provider. Not all concerns related directly to the building itself. Some residents spoke of the overly strict rules around the garden and the limitations placed on the types of planting and species of trees allowed. Whilst unrelated to the energy development, this appeared to add to a sense of imposition: "I quite like gardening. So that was a bit disappointing."

In terms of anti-social behavior, tenants have since taken ownership of these retrofitted dwellings, whereas previously these had been "trashed". The was now safer as a result of tripled glazed windows and had been transformed from one of England's most deprived areas to an area where some tenants "are now happy to invite friends over".

Overall, the residents were generally very positive about their retrofitted home. However, it was clear that there was a lack of control felt by the social housing residents about what they could, or could not do, in and around their flats after the retrofit. While this did not significantly impact on their experiences, it did leave some frustrated despite all the improved liveability outcomes from the low-energy housing.

\subsection{Catalyst housing, Horsham, Victoria}

The four low-energy houses were built to a 9 Nationwide House Energy Rating Scheme (NatHERS) Stars thermal comfort performance which translates to a predicted heating and cooling energy load of $25 \mathrm{MJ} / \mathrm{m}^{2} / \mathrm{yr}$ compared to the minimum building code requirement $6 \mathrm{Star}$ build $110 \mathrm{MJ} / \mathrm{m}^{2} / \mathrm{yr}$. This performance is close to the PassivHaus standard. The houses also included $1.5 \mathrm{~kW}$ photovoltaic systems on each property. These houses were occupied by low-income tenants with the housing provided by the Department of Human Services (a Victorian state government department). The analysis of the technical performance of the dwellings found they performed as expected. For example, as an average across the dwellings they purchased $62 \%$ less electricity, had $50 \%$ less $\mathrm{CO}_{2}$ impact and were thermally comfortable (without air conditioning) $10 \%$ more of the time [26].

As with the Manchester case study, the residents were generally very pleased with the houses and felt they performed extremely well. The residents reported lower ener- 
gy bills, improved thermal comfort and improved health and wellbeing outcomes. With a generous $(60 \mathrm{c} / \mathrm{kWh})$ feed-in-tariff from the photovoltaic systems, all households were in credit at different points across a year, with two being in credit at all times, even after three years:

"Look I haven't paid any off my power bill in six months and I'm still in credit...\$882 [currently in credit]."

In relation to thermal comfort they all found the housing to perform significantly better than previous dwellings.

"Well, we both feel the heat pretty well but when it was 42 degrees outside, it only got to $\left.29{ }^{\circ} \mathrm{C}\right]$ in here... when it was three degrees below zero this was 15 degrees inside on that morning, that's without any heaters being on, 15 degrees. So that's good."

While the experiences of the residents were generally positive, there were some issues raised. In particular there has been some difficulties early on in relation to the photovoltaic system. Initially when the residents moved in they were needing to complete the commissioning process to have the systems turned on. This proved challenging for the residents, but it was not long before the housing provider completed this process on their behalf. In addition, one of the systems failed and another was accidentally switched off. These issues were not picked up until the next energy bill cycles and required residents to follow up with the housing provider for maintenance. While these issues were ultimately fixed, one resident estimated they lost around \$200 in solar feed-in-tariffs while their system was off. This is no fault of the housing provider or the residents but highlights the challenges of both understanding how different sustainability elements work and how to maintain them.

While most of the residents seem to be using their dwellings as designed, one household challenged one of the key design features. The dwellings included high celestial windows which when combined with a ceiling fan were meant to help vent hot air during the summer. However, this household felt the windows were on the wrong orientation and in fact let more hot air in than it let out.

Overall, it was clear the occupants in the houses were satisfied with them and were very house proud during all the site visits for the research. As with the Manchester case, there were some points raised which related to the tenure of the housing and around how much control the households had.

\subsection{Lochiel Park, Adelaide, South Australia}

Unlike the previous two cases, Lochiel Park contained a combination of mainly owner-occupier detached and semi-detached houses, and also 23 low-income/affordable housing apartments. All dwellings were designed to achieve a NatHERS rating of 7.5 stars (a predicted heating and cooling energy load of $<58 \mathrm{MJ} / \mathrm{m}^{2} /$ year) which was significantly higher than the minimum requirement at the time of their design and construction (5-6 stars) and the development is still regarded as an exemplar of sustainable housing in Australia.

The apartments were built in response to a new requirement at the time of a minimum allocation of $15 \%$ affordable housing within a new development in SA. Note 
that seven of the 23 apartments are owner occupied, however the remaining are owned by government or private agencies, and that interviews have not yet been carried out with those in these apartments as the residents frequently change. From some preliminary discussions with tenants in the apartments, many have noticed the significant thermal comfort improvement from previous dwellings and that they have a device that provides heating and cooling. Despite the highly efficient reverse cycle air conditioner installed in each apartment, many commented that it this was somewhat frustrating to use, as it only has one vent/outlet in the living room, and that a lack of cooling or heating in the bedrooms was disappointing.

The houses at Lochiel Park are predominantly owner-occupier and are mostly detached housing; in this regard most of the initial owners of the properties would have had some level of say over the design, performance and finish of the dwellings. In addition to high thermal performance, the houses also included other sustainability elements such as: solar passive design (correct orientation etc.), double-glazed windows, gas-boosted solar water heaters, high-efficient appliances, rainwater harvesting and include a grid-connected photovoltaic system of size $1.0 \mathrm{~kW}_{\mathrm{p}} / 100 \mathrm{~m}^{2}$ of habitable floor area. Research over more than a decade since the initial homes were constructed have found they performed well in comparison to the initial targets discussed earlier (e.g. 64\% reduction in net energy compared with target of 66\%), as well as across a range of other metrics, with some achieving a net zero energy performance outcome $[18,24]$.

This quantitative performance is supported in the most part with the qualitative data from the households. As with the previous two case studies, almost all households perceived their home to be more sustainable, have lower bills, improved thermally comfort and improved health and wellbeing outcomes in comparison to their previous home.

"More comfortable, heaps more. When you get up in the morning it's not cold. ... It seems to run about ten degrees lower [from the maximum] in summer, and ten degrees higher [from the minimum] in winter."

"Yes, there is no doubt that this is a lot less to run than our last house."

However, while the households were overall very happy with their housing, there were still some issues raised. For example, some households found their experiences of comfort was not uniform across the seasons. Two fifths of the households mentioned that they suffered periods of discomfort during summer heatwaves and almost all said that the upstairs areas were uncomfortable during summer's higher temperatures. In some respect the occupants seemed surprised that this was the case given the eco credentials of the development. This is less surprising for researchers given that NatHERS is based on the design of the house and the quality of the build, and that NatHERS predicts a thermal energy load and subsequent star rating and does not rate a dwelling on expected temperatures or levels of thermal comfort; this is one common criticism of the NatHERS scheme.

Unlike the preceding case studies, most of the households in Lochiel Park found the additional technology elements easy to operate, however two households expressed being uneasy or unsure about how to optimise the settings on their solar water heater. Operating a passive solar house was not perceived to be difficult, with most 
households stating they felt it is easy to operate the various shade and ventilation options to maintain desired levels of thermal comfort.

It was evident that the ownership of the housing in Lochiel Park, and relative freedom to influence design and technology outcomes initially, and then once constructed, gave the households more of a sense of control in relation to sustainability than the social housing case studies:

"It's easier to live more sustainably now. In the last house we spent a lot of money with little effect, but here it is much easier. It's also easier because a lot has been done for us and it has been cost effective to invest in improvements."

This case study has found that the experience of households in these purpose-built low-energy homes is overwhelmingly positive although residents were quick to point out that these homes are far from perfect.

\section{Discussion}

Across the three case studies it was clear that the households were generally very happy with their more sustainable dwellings. They recognized the benefits they provided including reduced bills, improved thermal comfort and improved health and wellbeing outcomes and these benefits applied across retrofit and new build and heating- and cooling-dominated climates, albeit through a small amount of case studies. While in the social housing cases the households were often aware that these houses were better for the environment, it was not a driving consideration for how they used the dwellings. However, for the owner-occupied dwellings in places like Lochiel Park, they have consciously chosen to live in a low-energy home, although this may not have been the primary reason for the choice of housing, and to some extent they are invested in the technologies and systems that deliver a low-energy outcome.

There were other differences as well relating to tenure. In the social housing examples, there was an expressed frustration around some elements of control. Given the reliance on high performance building fabric of low-energy housing, there may be even less that occupants can do to dwellings they are renting due to concerns about it negatively impacting on performance. The PassivHaus Standard for example is very strict about the performance of air tightness so anything which puts holes into the walls (e.g. for a satellite) would likely compromise the performance. Whilst a sense of control can be considered intrinsically valuable for tenant wellbeing, the examples in Manchester, including window cleaning, access to satellite television, and personalization of gardens, directly affect aspects of quality of life that were clearly important to tenants. They also related to factors such as choice of energy supplier, that which could, although there is no evidence that they did, affect tenant's day to day costs.

These case studies also suggest that tenancy has a bearing on how householders learn about and get the best energy performance out of their building. Whilst some of the Manchester tenants felt they did not understand all the technical aspects, they benefitted from booklets produced by the housing provider that were specially tailored to their situation and to advice from housing staff; this was similar to the Horsham example. 
Part of the challenges of tenure highlighted in this paper are also likely to do with the fact that low-energy housing remains a niche housing performance and so the broader public has not yet typically had experiences of what it means and may not have experience in the energy practices necessary to achieve high performance. It will take time to educate households about low-energy houses and what it means to live in them and how they can, and cannot, be used. In some ways this relates to households needing to leave behind their old housing energy practices.

\section{Conclusion}

This paper set out to explore whether tenure impacts on how occupants experience low-energy homes. The evidence collected from these three case studies highlights two important findings in relation to tenure and low-energy homes: (a) there is no discernable difference in regard to the positive nature of the experience; and (b) for renters, it is noticeable low-energy homes provide additional constraints and freedoms beyond which they experienced in previous homes. In all case studies it is clear that residents of low-energy homes enjoy heightened levels of thermal comfort, greater access to the energy services they desire, lower energy bills, and associated health and wellbeing benefits. For renters who may not have the same level of choice about where they live, there is a noticeable frustration due to the addition of new constraints that come with not being able to make changes that alter the efficiency of the high performance building fabric. Yet at the same time, the financial freedom of lower or non-existent energy bills, releases low income households to take further action. Looking at this from the perspective of agency and capacity for action, it may be that to some extent low-energy homes provide no change to the physical capacity for action but may increase the financial capacity for action. There is also some emerging evidence that low-energy homes may increase resident's agency for change, whereby households in low-energy homes may feel obliged or encouraged to take further sustainability actions. In conclusion, the deeply personal nature of the benefits experienced in low-energy homes means that although the benefits were similar irrespective of tenure, the impact of those benefits may be greater to renters, particularly those on lower incomes.

\section{References}

[1] R. Horne, Housing Sustainability in Low Carbon Cities, Taylor \& Francis Ltd, London, 2017.

[2] IPCC, Fifth Assessment Report. Climate Change 2014: Working Group III: Mitigation of Climate Change., in, Intergovernmental Panel on Climate Change, Valencia, Spain, 2014.

[3] United Nations, Sustainable development goals, in, United Nations, New York, 2015.

[4] S. Berry, K. Davidson, Improving the economics of building energy code change: A review of the inputs and assumptions of economic models, Renewable and Sustainable Energy Reviews, 58 (Supplement C) (2016) 157-166. 
[5] W. Bradshaw, E. Connelly, M. Fraser Cook, J. Goldstein, J. Pauly, The costs \& benefits of green affordable housing, in: N. Ecology (Ed.), 2005.

[6] M. Jakob, Marginal costs and co-benefits of energy efficiency investments: The case of the Swiss residential sector., Energy Policy, 34 (2) (2006) 172-187.

[7] N. Mithraratne, B. Vale, R. Vale, Sustainable living: the role of whole life costs and values., Elsevier Limited, Oxford, 2007.

[8] G. Kats, Greening our built world: costs, benefits, and strategies., Island Press, Washington DC, 2009.

[9] T. Moore, Facilitating a transition to zero emission new housing in Australia: Costs, benefits and direction for policy, School of Global, Urban and Social Studies, RMIT University, 2012.

[10] B. Boardman, Examining the carbon agenda via the $40 \%$ House scenario, Building Research and Information, 35 (4) (2007) 363-378.

[11] B. Boardman, Fuel Poverty, in: S.J. Smith (Ed.) International Encyclopedia of Housing and Home, Elsevier, San Diego, 2012, pp. 221-225.

[12] G. Walker, R. Day, Fuel poverty as injustice: Integrating distribution, recognition and procedure in the struggle for affordable warmth, Energy Policy, 49 (0) (2012) 69-75.

[13] Peabody, BedZED., in, 2017.

[14] Living Building Challenge, zHome, Issaquah, Washington, in, 2015.

[15] Mira Heinze, Prof. Karsten Voss, Goal: Zero Energy Building Exemplary Experience Based on the Solar Estate Solarsiedlung Freiburg am Schlierberg, Germany, Journal of Green Building, 4 (4) (2009) 93-100.

[16] Sustainability House, Identifying Cost Savings through Building Redesign for Achieving Residential Building Energy Efficiency Standards. Part two., in, Prepared for the Department of Climate Change \& Energy Efficiency, Canberra, 2012.

[17] T. Moore, Modelling the through-life costs and benefits of detached zero (net) energy housing in Melbourne, Australia, Energy and Buildings, 70 (0) (2014) 463-471.

[18] S. Berry, D. Whaley, K. Davidson, W. Saman, Do the numbers stack up? Lessons from a zero carbon housing estate, Renewable Energy, 67 (2014) 80-89.

[19] B. Vale, R. Vale, The new autonomous house: design and planning for sustainability., Thames \& Hudson, London, 2000.

[20] S. Berry, The technical and economic feasibility of applying a net zero carbon standard for new housing, School of Engineering, Division of Information Technology, Engineering and the Environmen, University of South Australia, 2014.

[21] Å.L. Sørensen, A.G. Imenes, S. Grynning, T.H. Dokka, Energy measurements at Skarpnes zero energy homes in Southern Norway: Do the loads match up with the on-site energy production?, Energy Procedia, 132 (2017) 567-573.

[22] S.-K. Kim, S.-J. Lee, H.J. Kwon, M. Ahn, Zero-energy home development in Korea: energy-efficient and environmentally friendly design features and future directions, Housing and Society, 42 (3) (2015) 222-238.

[23] W.D. Thomas, J.J. Duffy, Energy performance of net-zero and near net-zero energy homes in New England, Energy and Buildings, 67 (2013) 551-558.

[24] S. Berry, D. Whaley, K. Davidson, W. Saman, Near zero energy homes - What do users think?, Energy Policy, 73 (2014) 127-137. 
[25] J. Zhao, K. Carter, Perceived Comfort and Adaptive Process of Passivhaus 'Participants', Energy Procedia, 83 (2015) 121-129.

[26] T. Moore, I. Ridley, Y. Strengers, C. Maller, R. Horne, Dwelling performance and adaptive summer comfort in low-income Australian households, Building Research \& Information, (2017) 1-14.

[27] J. Melvin, The split incentives energy efficiency problem: Evidence of underinvestment by landlords, Energy Policy, 115 (2018) 342-352.

[28] D. Charlier, Energy efficiency investments in the context of split incentives among French households, Energy Policy, 87 (2015) 465-479.

[29] S. Bird, D. Hernández, Policy options for the split incentive: Increasing energy efficiency for low-income renters, Energy Policy, 48 (2012) 506-514.

[30] R. Horne, T. Dalton, S. Moloney, Beyond the split incentive: governing socio-technical relations in private rental housing retrofit, in: M. Hodson, S. Marvin (Eds.) Retrofitting cities. Priorities, governance and experimentation, Earthscan, New York, 2016.

[31] B. Mashhoodi, Spatial dynamics of household energy consumption and local drivers in Randstad, Netherlands, Applied Geography, 91 (2018) 123-130.

[32] A. Druckman, T. Jackson, Household energy consumption in the UK: A highly geographically and socio-economically disaggregated model, Energy Policy, 36 (8) (2008) 3177-3192.

[33] E. Hache, D. Leboullenger, V. Mignon, Beyond average energy consumption in the French residential housing market: A household classification approach, Energy Policy, 107 (2017) 82-95.

[34] N. Isaacs, K. Saville-Smith, M. Camilleri, L. Burrough, Energy in New Zealand houses: comfort, physics and consumption, Building Research \& Information, 38 (5) (2010) 470-480.

[35] M. Gabriel, P. Watson, R. Ong, G. Wood, M. Wulff, The environmental sustainability of Australia's private rental housing stock, in, Australian Housing and Urban Research Institute, Melbourne, Australia, 2010.

[36] Y. Parag, S. Zur, N. Raz, Levels of consumers' agency and capacity as predictors for electricity demand reduction in the residential sector, Energy Efficiency, 10 (3) (2017) 597 611.

[37] G. Wood, R. Ong, M. Cigdem, Housing affordability dynamics: new insights from the last decade, in, Australian Housing and Urban Research Institute, Melbourne, Australia, 2014.

[38] T. Moore, Y. Strengers, C. Maller, Utilising Mixed Methods Research to Inform Lowcarbon Social Housing Performance Policy, Urban Policy and Research, 34 (3) (2016) 240-255.

[39] G. Sherriff, P. Martin, B. Roberts, Erneley Close Passive House Retrofit: Resident experiences and building performance in retrofit to passive house standard in, University of Salford 2018. 